\title{
Research on floor improvement based on equipment layout optimization
}

\author{
Xiaobing $\mathrm{Pei}^{1}$, Qiannan $\mathrm{He}^{2, \mathrm{a}}$ \\ 1,2Tianjin University of Technology, Tianjin 300384, China \\ a13752157389@163.com
}

Keywords: floor improvement, equipment layout, lean production, model

\begin{abstract}
The level of floor management can reflect directly operating conditions of enterprise. Therefore, it's crucial to improve floor management for development of enterprises. Workshop equipment layout design is an important part in the planning of the manufacturing system, the result have a deep influence on material handling cost, handling efficiency and even the production efficiency of production system operation. Rational equipment layout can help realize the efficient allocation of production factors, reduce production cost, improve production efficiency and product quality, make the enterprise to improve their competitiveness. The paper proposes equipment layout optimization model based on the lean thinking, to make the efficiency of workshop promote.
\end{abstract}

\section{Introduction}

With the development of world economic globalization and diversification, the market also gradually shift from a seller's market to a buyer's market. The competition between enterprises is no only a price competition, but as to product design, quality, cost, delivery time, response speed and after-sales service to its customers' needs and supply chain as the center of the comprehensive strength of the competition. So the manufacturing companies focused on more applicable for small batch and many varieties, low consumption of production management--lean production.

Production site is the place of enterprise directly to create efficiency, the original source of the enterprise all the information, and the places of many questions germination. Floor improvement is the deepening of site management, is the problems found during the field management to analyze and solve in a planned way, step by step optimization is a never-ending process. The paper mainly aim at equipment layout problems to improve production site.

\section{Equipment layout optimization}

Equipment layout optimization is a foundational question of floor improvement activities, its rationality affects directly the field of production capacity, work efficiency and production cost. Tompkins and Whiet ${ }^{[1]}$ pointed out that operation cost of unreasonable equipment layout account for $20 \% \sim 50 \%$ of the total manufacturing costs, and superior equipment layout can reduce the cost by 10\% 30\%; Superior equipment layout can also speed up the materials handling efficiency, reduce the residence time of articles being processed, reduce the capacity of workpiece buffer, reduce the occupied space of manufacturing system, reduce the manufacturing system of the construction cost. Therefore, good equipment layout is very important.

\subsection{Equipment layout problem description}

Equipment layout of manufacturer enterprise generally can have two types of "logical layout" and "physical layout",2]. Logical layout refers to the task allocation of manufacturing systems, including resource planning and load balancing, etc; Physical layout refers to allocate corresponding position for manufacturing equipment. In this article, layout is mainly site physical layout of equipment.

Equipment layout refers to arrange reasonably all equipments of within the workplace, under meeting the device area and the position constraint conditions, make them combine into a certain 
space form, thereby, service effectively for enterprise's production operation, in order to obtain better economic effects ${ }^{[3]}$. Common job shop layout includes the single-row layout, line layout, the u-shaped layout and circular layout, etc.

Satisfying one of the following conditions, we will need to improve or redesign the job shop layout:

1) Product changes, including appearance, variety and quantity of the three changes;

2) Technology refresh. With the rising of production technology, the workshop will eliminate gradually the old equipment, bring in new equipment. If new equipment has a certain comprehensive function, the relationship between the location of the old and new equipment will appear antinomy, therefore, needing to adjust the existing equipment layout;

3) In operation stage, if Job shop exists following phenomenon, such as long material flow distance, confusion logistics direction, articles being processed etc, it need to improve equipment layout.

\subsection{Workshop facility layout goals and principles}

When job-shop facility layout is designed or improved, achieve the following goals:1)Material production line simplified, smooth logistics;2)Shorten the production cycle;3) As far as possible to reduce transport distance or avoid handling; 4)Effective use of limited space;5)in favor of managers control;6) Provide the operator with a safe and convenient work environment ${ }^{[4-5]}$.

\subsection{The model of Equipment layout problem}

In fact, single line layout, the u-shaped layout and circular layout can be regarded as kinds of line layout. The geometric model of kinds of line layout, as shown in the figure 1.

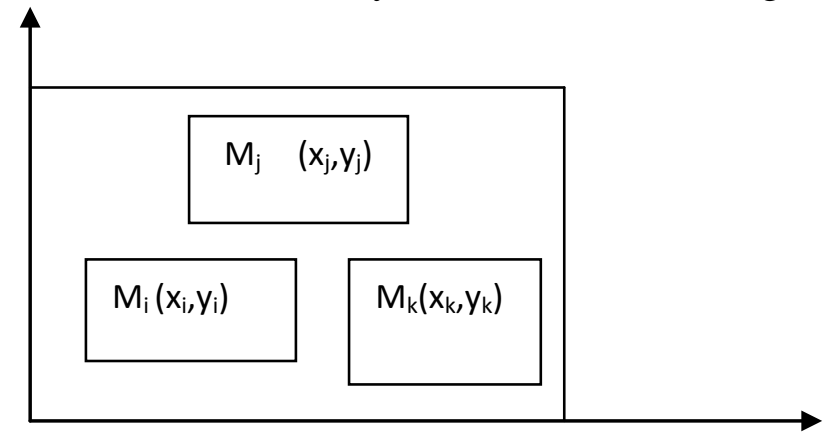

Figure 1 The geometric model of equipment layout

Cross-sectional views of the figure is working on facilities layout, diagram $M_{\mathrm{i}}$ on behalf of facility $\mathrm{i},\left(\mathrm{x}_{i}, y_{i}\right)$ on behalf of facility i central coordinates. Coordinates The facilities layout problem refers to solve various equipment $\left(x_{i}, y_{i}\right)$ and make it meet certain objective function requirements.

Solving facility layout problem common model is the secondary allocation model (QAP), its idea: the workspace fall into $m$ regions of equal area, then $n(n=m)$ units assigned to these areas, respectively, making minimize the total handling cost. And each region only put up an equipment.

Mathematical expressions of QAP model:

$$
\min \sum_{i=1}^{\mathrm{n}} \sum_{j=1}^{n} \sum_{k=1}^{m} \sum_{l=1}^{m} \mathrm{c}_{\mathrm{o}} f_{i j} d_{k 1} X_{i k} X_{j l}
$$

s.t.

$$
\begin{gathered}
x_{i j}=\left\{\begin{array}{l}
1 \quad \text { when equipment } \mathrm{i} \text { placed in position } \mathrm{j} \\
0 \text { when equipment } \mathrm{i} \text { not placed in position } \mathrm{j}
\end{array}\right. \\
\sum_{j=1}^{m} x_{i j}=1, i=1,2, \cdots, \mathrm{n} \\
\sum_{i=1}^{n} x_{i j}=1, j=1,2, \cdots, m
\end{gathered}
$$


among: $\mathrm{c}_{o}$ is carrying costs of unit distance; $f_{i j}$ is logistics frequency of equipment $\mathrm{i}$ to $\mathrm{j} ; d_{k l}$ is the distance between $\mathrm{k}$ and $\mathrm{l}$.

\section{Examples of application}

According to the actual production situation of workshop, a device layout model as shown in the figure. $M_{\mathrm{i}}$ on behalf of facility $\mathrm{i},\left(\mathrm{x}_{i}, y_{i}\right)$ on behalf of facility i central coordinates. $\mathrm{a}_{i}$ and $b_{i}$ represents the length and width of equipment $i, L_{o}$ represents the minimum distance between two rows of equipment, $d_{o}$ represents minimum distance in one row of equipment, $l$ and h represents workshop of length and width, respectively.

Optimized layout with two-row layout form, the model satisfies the following constraints:

Any equipment must be in length 1 , width $h$ of area; Between any two adjacent devices on the same line in the $\mathrm{x}$ direction distance greater than or equal to $\mathrm{d}_{o}$; Is not in the same line the distance between any two devices in the y direction is greater than or equal to $L_{o}$; The total length of facility layout in the $\mathrm{x}$ direction is less than or equal to the length of the workshop 1; The total length of facility layout in the y direction is less than or equal to the width of the workshop h.

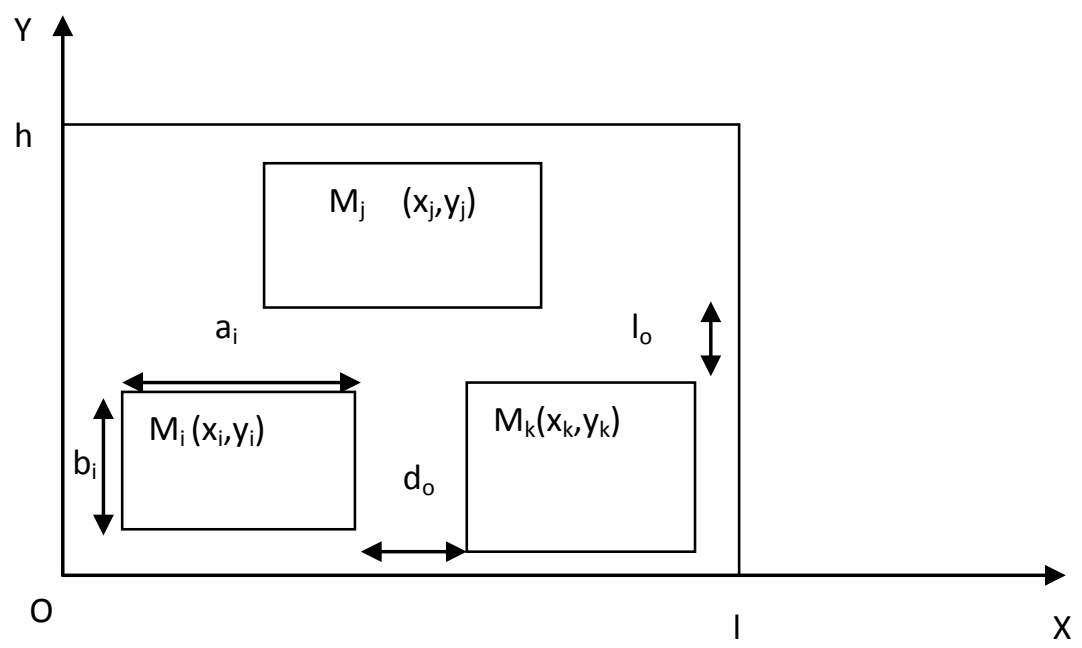

Figure 2 The geometric model of equipment layout

According the above constraints, a mathematic model of the equipment layout as below:

$$
\begin{aligned}
& Z=\min \left(\sum_{i=1}^{11} \sum_{j=1}^{11} Q_{i j} D_{i j}\right)=\min \left(\sum_{i=1}^{11} \sum_{j=1}^{11} Q_{i j}\left(\left|x_{i}-x_{j}\right|+\left|y_{i}-y_{j}\right|\right)\right) \\
& \frac{a_{i}}{2} \leq x_{i} \leq 1-\frac{a_{i}}{2} ; \frac{b_{i}}{2} \leq y_{i} \leq h-\frac{b_{i}}{2} ; \\
& \left|x_{i}-x_{j}\right| h_{i, k} h_{j, k}-\frac{1}{2}\left(a_{i}+a_{j}\right) \geq d_{o} ;\left|\mathrm{y}_{i}-y_{j}\right| h_{i, 1} h_{j, 2}-\frac{1}{2}\left(b_{i}+b_{j}\right) \geq 1_{o} ; \\
& \max \left(x_{i}\right)-\min \left(x_{i}\right)+\frac{1}{2}\left(a_{\max }+a_{\min }\right) \leq 1 ; \max \left(y_{i}\right)-\min \left(y_{i}\right)+\frac{1}{2}\left(b_{\max }-b_{\min }\right) \leq h ; \\
& h_{i, k}\left\{\begin{array}{l}
1 \text { The equipment } \mathrm{i} \text { is in the } \mathrm{k} \text { line } \\
0 \text { The equipment } \mathrm{i} \text { is not in the } \mathrm{k} \text { line }
\end{array}\right. \text {; } \\
& \mathrm{i}, \mathrm{j}=1,2, \ldots, 11 ; \mathrm{k}=1,2
\end{aligned}
$$

$\mathrm{x}_{i}, y_{i}$ respents coordinate of equipment $\mathrm{I} ; a_{i}$ and $b_{i}$ respectively, respents the length and width of equipment $\mathrm{i} ; l_{o}$ represents the minimum distance between two rows of equipment; $\mathrm{d}_{\text {o }}$ represents minimum distance in one row of equipment; $l$ and h respectively for the length and width 
of the shop; $\max \left(x_{i}\right)$ and $\min \left(x_{i}\right)$ indicate maximum and minimum coordinates in the $\mathrm{x}$ direction, $a_{\max }$ and $a_{\min }$ represents the x coordinate in the direction the maximum and minimum of two units long, situation is similar in the y direction.

\section{Conclusion}

Floor improvement is a key issue in production management, affects directly the efficiency of the production, costs of production and quality of production. On the basis of existing research, this paper combined the lean thinking, propose site improvement method based on equipment layout optimization, to improve the level of the floor improvement. The paper proves that equipment layout optimization improves the enterprise production site conditions, reduces production costs, increases production efficiency.

\section{References}

[1]Changan Zhu, Jiyang Qi, Yi Zeng. Research on equipment layout based on genetic tabu hybrid search algorithm. Systems engineering and electronics, Vol 28(2006),No 4,p. 630-632.

[2]Chuan Zhao:Study on Optimization Model and Solution Algorithm of Mechanical Workshop Equipment Layout.( Degree of Master of Management, College of Mechanical Engineering of Chongqing University, China,2010).p.1-105.

[3] Raoot R, Rakshit Jr. Hybrid ant systems for the dynamic facility layout problem, Computers and Operations Research, Vol 33(2006),p.790-803.

[4] Changan Zhu, Jiyang Qi. Improved simulated annealing algorithm in the application of the equipment layout design. Computer engineering, Vol 33(2007), No 1,p.241-243.

[5]Shutian Yan, Huixiang Huang, Wenjuan Wu. The design of facility layout of RMS based on genetic algorithms and its simulation.Modern manufacturing engineering.Vol 6(2010),p.40-43. 